\title{
Mineração
}

\section{Avaliação de alguns agentes lixiviantes para a remoção do cobre contido em um minério complexo de ouro}

\author{
Fabiana Albuquerque Cunha \\ Graduanda do Curso de Engenharia Química da Universidade Federal de Minas Gerais. \\ E-mail:fabiana_ac@hotmail.com \\ Afonso Henriques Martins \\ D.Sc., M.Sc., Professor Adjunto do Departamento de Engenharia Metalúrgica \\ e de Materiais da Universidade Federal de Minas Gerais. \\ E-mail:ahmartin@demet.ufmg.br
}

\section{Resumo}

Alguns minérios complexos de ouro e cobre apresentam a característica de possuírem elevados teores de cobre, inviabilizando a utilização direta do processo de cianetação para extração do ouro.

Esse trabalho apresenta os resultados experimentais de uma rota hidrometalúrgica para o pré-tratamento do minério de ouro e cobre visando a maximizar a remoção de cobre e a viabilizar a etapa seguinte de cianetação. Foram realizados experimentos de lixiviação utilizando $\mathrm{H}_{2} \mathrm{SO}_{4}, \mathrm{Fe}_{2}\left(\mathrm{SO}_{4}\right)_{3}, \mathrm{H}_{2} \mathrm{O}_{2}, \mathrm{HCl}, \mathrm{HClO}_{4}$ e $\mathrm{NH}_{4} \mathrm{OH}$. Entre esses ensaios, as melhores extrações de cobre - próximas a $50 \%$ - foram obtidas em experimentos com duração de 15 minutos utilizando ácido sulfúrico a $82 \pm 2^{\circ} \mathrm{C}$ e uma combinação de ácido sulfúrico e peróxido de hidrogênio a $25 \pm 2^{\circ} \mathrm{C}$.

Os resultados obtidos foram inferiores àquele percentual mínimo de extração de cobre (aproximadamente 95\%) necessário para viabilizar economicamente a etapa posterior de cianetação para a extração de ouro.

Palavras-chave: cobre, ouro, lixiviação.

\section{Abstract}

Some complexed gold ores present high percent of copper content and it inhibits the direct use of classical hydrometallurgical cyanidation process for gold recovery.

This paper presents the experimental results of a hydrometallurgical route for gold ore pre-treatment aiming at extracting copper for further cyanidation. Some experiments were carried out using $\mathrm{H}_{2} \mathrm{SO}_{4}$, $\mathrm{Fe}_{2}\left(\mathrm{SO}_{4}\right)_{3}, \mathrm{H}_{2} \mathrm{O}_{2}, \mathrm{HCl}, \mathrm{HClO}_{4}$ and $\mathrm{NH}_{4} \mathrm{OH}$. The highest percent of copper extracted (50\%) was obtained for using sulfuric acid at $82 \pm 2^{\circ} \mathrm{C}$ during 15 minutes, and using a combination of sulfuric acid and hydrogen peroxide at $25 \pm 2^{\circ} \mathrm{C}$ during 15 minutes.

The experimental results of this work were lower than $95 \%$ percent of copper extracted and considered unsuitable for the cyanidation stage and gold recovery.

Keywords: copper, gold, leaching. 


\section{Introdução}

O tratamento de minérios auríferos baseia-se nas diferenças marcantes das propriedades do ouro em relação às gangas. A alta densidade, a solubilidade desse metal em soluções alcalinas diluídas de cianeto, a capacidade de formar amálgamas com mercúrio e a boa resposta ao processo de flotação constituíram as bases dos fluxogramas de processo mais simples e usuais.

A descoberta de grandes reservas de minérios complexos de ouro e cobre vem ocasionando o aumento do volume de pesquisas relacionadas ao tema. $\mathrm{O}$ alto valor associado a esses metais, a geração de alguns problemas ambientais e a perspectiva de viabilidade econômica justificam o desenvolvimento de soluções inovadoras para seleção de uma rota de processo que maximize suas recuperações com menores custos.

A literatura indica que uma das alternativas de processo mais promissoras para o aproveitamento desse tipo de minério consiste de uma lixiviação ácida agitada, seguida de cianetação do rejeito.

Esse trabalho apresenta os resultados experimentais obtidos com base em uma rota hidrometalúrgica para o tratamento do minério de ouro e cobre de Igarapé Bahia, visando a maximizar a remoção do cobre, de forma a viabilizar a etapa seguinte de cianetação para recuperação do ouro.

\section{Materiais e métodos}

A metodologia adotada nesse trabalho compreende a execução de experimentos de lixiviação, utilizando diferentes agentes lixiviantes. A caracterização inicial do minério foi efetuada, assim como a dos produtos após cada série de experimentos. As análises químicas foram realizadas por meio de Espectrofotometria de Absorção Atômica (AAS) para determinação das concentrações de $\mathrm{Cu}$.

As amostras utilizadas nos ensaios consistiram do minério oxidado da mina de Igarapé Bahia (Companhia Vale do Rio Doce).
A unidade experimental consistiu de um reator cilíndrico de vidro borossilicato de $300 \mathrm{~mL}$ de capacidade nominal e cano longo, tendo um agitador mecânico com controle de intensidade de agitação acoplado ao reator. A temperatura no sistema foi mantida constante por meio de um banho de areia posicionado sobre uma placa aquecedora elétrica. $\mathrm{O}$ acompanhamento da temperatura foi efetuado por meio de um termômetro de mercúrio. O tempo de lixiviação foi medido através de um cronômetro manual.

\subsection{Experimentos de Lixiviação}

Experimentos de lixiviação do minério oxidado de Igarapé Bahia foram conduzidos utilizando-se diferentes agentes lixiviantes, visando a determinar os percentuais de extração de cobre obtidos. As amostras utilizadas possuíam teores médios de $\mathrm{Cu}$ e $\mathrm{Au}$ iguais a $0,55 \%$ e $3,54 \mathrm{~g} / \mathrm{t}$, respectivamente.

Mendes (1999) estudou uma rota hidrometalúrgica para o pré-tratamento do minério de transição de Igarapé Bahia, por meio da lixiviação sulfúrica agitada. Esse minério apresentou teores médios de $\mathrm{Cu}$ e Au de 1,93\% e 1,76 g/t, respectivamente. As condições ótimas experimentais empregadas nos ensaios de lixiviação inicialmente realizados [A] são mostradas na Tabela 1.

Em seguida, foram realizados experimentos onde se variou cada um dos parâmetros de maior influência na lixivi- ação sulfúrica agitada a dois níveis experimentais diferentes. Nesses experimentos [B], objetivou-se verificar se as condições ótimas utilizadas nos ensaios anteriores (determinadas por Mendes, 1999, para o minério de transição) possibilitariam obter, também, a máxima extração de cobre para o minério oxidado.

A partir de então, foram realizados experimentos utilizando-se as condições adotadas nos ensaios [A] com a adição de quantidades de diferentes agentes lixiviantes. Na Tabela 2, encontram-se os reagentes e suas quantidades utilizadas em cada ensaio. Alguns desses ensaios foram realizados à temperatura ambiente, uma vez que a manipulação de agentes oxidantes fortes a altas temperaturas não é recomendada por razões de segurança.

As quantidades estequiométricas foram determinadas supondo-se que todo o cobre presente no minério estivesse sob a forma de calcopirita $(\mathrm{Cu}-$ $\mathrm{FeS}_{2}$ ). Essa suposição foi feita, pois esta é uma espécie muito resistente à oxidação e, desta forma, garantiram-se quantidades de oxidantes suficientes para a suposta oxidação plena de todas as espécies contendo cobre.

\section{Resultados e discussão}

A Tabela 3 mostra os resultados experimentais obtidos para a extração de cobre com o emprego dos diferentes agentes lixiviantes e as condições expe-

Tabela 1 - Condições experimentais adotadas para a realização dos ensaios de lixiviação sulfúrica agitada $[\mathrm{A}]$

\begin{tabular}{c|c}
\hline Variáveis & Valor adotado \\
\hline Temperatura* $^{*}$ & $82^{\circ} \mathrm{C}$ \\
\hline Granulometria do minério $^{*}$ & $60 \%<0,074 \mathrm{~mm}$ (200 Mesh) \\
\hline Intensidade de agitação* & $270 \mathrm{rpm}$ \\
\hline Percentagem de sólidos* & $40 \%$ \\
\hline Ácido sulfúrico adicionado* & $98,5 \mathrm{~kg} / \mathrm{t}$ \\
\hline Tempo de lixiviação* & $15 \mathrm{~min}$ \\
\hline * MENDES, 1999.
\end{tabular}


Tabela 2 - Agentes lixiviantes e suas concentrações relativas empregadas nos ensaios de lixiviação.

\begin{tabular}{|c|c|}
\hline Ensaio & Agente(s) Lixiviante(s) \\
\hline $\mathrm{C}$ & $\begin{array}{l}\mathrm{H}_{2} \mathrm{SO}_{4}(98,5 \mathrm{~kg} / \mathrm{t}) \text { e } \mathrm{Fe}_{2}\left(\mathrm{SO}_{4}\right)_{3} \text { (uma e duas vezes a } \\
\text { quantidade estequiométrica }(\mathrm{C} 1 \text { e } \mathrm{C} 2) \text { ) }\end{array}$ \\
\hline $\mathrm{D}$ & $\mathrm{H}_{2} \mathrm{O}_{2}(1 / 4$ da estequiométrica) \\
\hline $\mathrm{E}$ & $\mathrm{H}_{2} \mathrm{SO}_{4}(98,5 \mathrm{~kg} / \mathrm{t})$ e $\mathrm{H}_{2} \mathrm{O}_{2}(1 / 4$ da estequiométrica) \\
\hline $\mathrm{F}$ & $\begin{array}{l}\mathrm{H}_{2} \mathrm{SO}_{4}(98,5 \mathrm{~kg} / \mathrm{t}) \text { e } \mathrm{H}_{2} \mathrm{O}_{2}(1 / 4 \text { da estequiométrica) e } \\
\mathrm{Fe}_{2}\left(\mathrm{SO}_{4}\right)_{3} \text { (estequiométrica) }\end{array}$ \\
\hline G & $\mathrm{HCl}(98,5 \mathrm{~kg} / \mathrm{t})$ \\
\hline $\mathrm{H}$ & $\mathrm{HClO}_{4}(98,5 \mathrm{~kg} / \mathrm{t})$ \\
\hline I & $\mathrm{HClO}_{4}(98,5 \mathrm{~kg} / \mathrm{t})$ e $\mathrm{H}_{2} \mathrm{O}_{2}(1 / 4$ da estequiométrica) \\
\hline J & $\mathrm{CuO}$ e $\mathrm{NH}_{4} \mathrm{OH}$ e $\left(\mathrm{NH}_{4}\right)_{2} \mathrm{CO}_{3}$ estequiométrica \\
\hline
\end{tabular}

rimentais adotadas. Os resultados apresentados nessa tabela revelam que os ensaios [A] empregando as condições ótimas determinadas por Mendes (1999), atingindo $50 \%$ de extração, e os ensaios [E] utilizando a combinação de ácido sulfúrico e peróxido de hidrogênio, atingindo $49 \%$ de extração, foram aqueles que apresentaram as melhores extrações de cobre.

Pela comparação dos resultados obtidos nos experimentos [A] e [B] - ensaios com modificação de parâmetros da lixiviação, percebe-se que não foram alcançadas extrações de cobre superiores a $50 \%$. Esse fato comprova que as condições ótimas determinadas por Mendes (1999) para o minério de transição de Igarapé Bahia são também as condições que possibilitam a máxima extração de cobre para o minério oxidado. Dessa forma, foi confirmada a expectativa de utilização dessas mesmas condições para a máxima solubilização de cobre.

A análise dos resultados [C] - ensaios com ácido sulfúrico e sulfato férrico - revelou valores menores de extração que os conseguidos na lixiviação sulfúrica, nas mesmas condições, sem adição de sulfato férrico [A]. Além disso, percebeu-se que o incremento de $2 \%$ na extração obtida ao se dobrar a quantidade de sulfato férrico adicionado (resultados de [C1] e [C2]) não justificaria a utilização de quantidades elevadas desse reagente.

Nos experimentos de lixiviação realizados utilizando-se o peróxido de hidrogênio como agente lixiviante [D], foram conseguidas extrações de cobre próximas a 1,4\%. Valores de extração pouco expressivos já eram esperados, uma vez que durante a realização do experimento notou-se que praticamente todo o peróxido em solução teria se decomposto ao entrar em contato com o minério.

Os resultados obtidos nos experimentos [E] - ensaios com ácido sulfúrico e peróxido de hidrogênio - (49\% de extração), quando comparados aos obtidos em [B1] (25\% de extração), refletem o grande incremento conseguido na extração de cobre pela adição do peróxido de hidrogênio à solução de ácido sulfúrico. Diferentemente dos experimentos [D], apenas uma pequena parcela do peróxido de hidrogênio se decompôs ao entrar em contato com o minério, uma vez que a solução aquosa ácida reduz a sua decomposição (Dimitryevic et al., 1996).
Os valores de extração de cobre obtidos em [F] - ensaios com ácido sulfúrico, peróxido de hidrogênio e sulfato férrico - (29\% de extração) foram considerados baixos. Eles já eram esperados, uma vez que durante a realização do experimento notou-se que grande parte do peróxido em solução se decompôs antes mesmo de entrar em contato com o minério, pois os íons férricos, também presentes na solução, funcionaram como catalisadores da decomposição do peróxido (Dimitryevic et al., 1996).

Os resultados obtidos para a extração de cobre em [G] - ensaios com $\mathrm{HCl}$ (32\% de extração) - foram inferiores aos conseguidos nos ensaios utilizando as condições determinadas por Mendes (1999) [A] (50\% de extração). Contudo, ao se comparar à extração conseguida pelo ácido sulfúrico à temperatura ambiente [B1] (25\% de extração), percebe-se a sua maior capacidade de lixiviação de espécies contendo cobre em relação ao ácido sulfúrico, nas mesmas condições.

Nos experimentos realizados utilizando-se o ácido perclórico como agente lixiviante $[\mathrm{H}]$, foram conseguidas extrações de cobre próximas a $22 \%$. Notou-se que foram alcançados valores de extração de cobre inferiores aos conseguidos em [A] (50\% de extração), em [B1] - ensaios utilizando ácido sulfúrico à temperatura ambiente - $(25 \%$ de extração), e [G] - ensaios com ácido clorídrico - (32\% de extração). Assim, concluiu-se que o ácido perclórico foi menos eficiente para lixiviar espécies contendo cobre.

Nos ensaios nos quais empregouse o ácido perclórico com a adição de peróxido de hidrogênio [I], foram alcançadas extrações de cobre próximas a $43 \%$. Apesar de esses resultados mostrarem valores de extração de cobre inferiores aos alcançados nos ensaios [A] (50\% de extração), notou-se o grande incremento conseguido na extração de cobre pela adição do peróxido de hidrogênio, quando esse resultado é comparado ao experimento utilizando-se somente o ácido perclórico $[\mathrm{H}]$ (22\% de extração).

Nos experimentos de lixiviação realizados, empregando-se uma solução de óxido de cobre II, hidróxido de amônio e carbonato de amônio [J], foram conse- 
Tabela 3 - Resultados obtidos nos experimentos de lixiviação.

\begin{tabular}{|c|c|c|c|c|}
\hline Experimento (notação) & Agente Lixiviante $(\mathrm{kg} / \mathrm{t})$ & $\begin{array}{c}\text { Temperatura } \\
\left({ }^{\circ} \mathrm{C}\right)\end{array}$ & $\begin{array}{l}\text { Tempo } \\
\text { (min) }\end{array}$ & $\begin{array}{c}\text { Extração de } \\
\mathrm{Cu}(\%)\end{array}$ \\
\hline $\mathbf{A}$ & $\mathrm{H}_{2} \mathrm{SO}_{4}(98,5)$ & 82 & 15 & 50 \\
\hline B1 & $\mathrm{H}_{2} \mathrm{SO}_{4}(98,5)$ & 25 & 15 & 25 \\
\hline B1a & $\mathrm{H}_{2} \mathrm{SO}_{4}(98,5)$ & 50 & 15 & 34 \\
\hline B2 & $\mathrm{H}_{2} \mathrm{SO} 4(50)$ & 82 & 15 & 39 \\
\hline $\mathrm{B} 2 \mathrm{a}$ & $\mathrm{H}_{2} \mathrm{SO}_{4}(150)$ & 82 & 15 & 45 \\
\hline B3 & $\mathrm{H}_{2} \mathrm{SO}_{4}(98,5)$ & 82 & 30 & 46 \\
\hline B3a & $\mathrm{H}_{2} \mathrm{SO}_{4}(98,5)$ & 82 & 60 & 47 \\
\hline B3b & $\mathrm{H}_{2} \mathrm{SO}_{4}(98,5)$ & 82 & 90 & 47 \\
\hline B3c & $\mathrm{H}_{2} \mathrm{SO}_{4}(98,5)$ & 82 & 120 & 49 \\
\hline $\mathrm{C} 1$ & $\mathrm{H}_{2} \mathrm{SO}_{4}(98,5)+\mathrm{Fe}_{2}\left(\mathrm{SO}_{4}\right)_{3}(69,2)$ & 82 & 15 & 44 \\
\hline $\mathrm{C} 2$ & $\mathrm{H}_{2} \mathrm{SO}_{4}(98,5)+\mathrm{Fe}_{2}\left(\mathrm{SO}_{4}\right)_{3}(138,5)$ & 82 & 15 & 46 \\
\hline $\mathrm{D}$ & $\mathrm{H}_{2} \mathrm{O}_{2}(5,89)$ & 25 & 15 & 1,4 \\
\hline $\mathbf{E}$ & $\mathrm{H}_{2} \mathrm{SO}_{4}(98,5)+\mathrm{H}_{2} \mathrm{O}_{2}(5,89)$ & 25 & 15 & 49 \\
\hline $\mathrm{F}$ & $\begin{array}{c}\mathrm{H}_{2} \mathrm{SO}_{4}(98,5)+\mathrm{H}_{2} \mathrm{O}_{2}(5,89)+ \\
\mathrm{Fe}_{2}\left(\mathrm{SO}_{4}\right)_{3}(69,2)\end{array}$ & 25 & 15 & 29 \\
\hline $\mathrm{G}$ & $\mathrm{HCl}(98,5)$ & 25 & 15 & 32 \\
\hline $\mathrm{H}$ & $\mathrm{HClO}_{4}(98,5)$ & 25 & 15 & 22 \\
\hline 1 & $\mathrm{HClO}_{4}(98,5)+\mathrm{H}_{2} \mathrm{O}_{2}(5,89)$ & 25 & 15 & 43 \\
\hline$J$ & $\begin{array}{c}\mathrm{CuO}(6,89)+\mathrm{NH}_{4} \mathrm{OH}(12,1)+ \\
\left(\mathrm{NH}_{4}\right)_{2} \mathrm{CO}_{3}(10,4)\end{array}$ & 25 & 120 & 28 \\
\hline
\end{tabular}

guidas extrações de cobre próximas a $28 \%$, valores também considerados baixos. Esses experimentos foram conduzidos com o objetivo de se compararem as extrações de cobre obtidas em soluções ácidas (ensaios A, B, C, E, F, G, H e I) e em uma solução básica.

\section{Conclusões}

No estudo da utilização de diferentes reagentes químicos como agentes lixiviantes para o tratamento hidrometalúrgico de amostras de minério oxidado de Igarapé Bahia, foram realizadas as seguintes constatações:

- Os ensaios que forneceram os melhores resultados com relação à extração de cobre (próximos a 50\%) foram aqueles com duração de 15 minutos utilizando ácido sulfúrico a $82 \pm 2^{\circ} \mathrm{C}$ e uma combinação de ácido sulfúrico e peróxido de hidrogênio a $25 \pm 2^{\circ} \mathrm{C}$.
- As condições experimentais ótimas determinadas por Mendes (1999) para o minério de transição foram também as condições que possibilitaram a máxima extração de cobre para o minério oxidado de Igarapé Bahia.

- A adição de peróxido de hidrogênio à solução lixiviante gerou um grande incremento na extração de cobre atingida, à temperatura ambiente. Verificou-se esse fato nas soluções de ácido sulfúrico (extração de cobre saltou de $25 \%$ para $49 \%$ ) e nas soluções de ácido perclórico (incremento de $22 \%$ para 43\%).

Alcançaram-se valores de extração representativos, contudo não foi atingida a extração de cobre necessária (aproximadamente $95 \%$ ) para viabilizar economicamente a etapa posterior de cianetação visando à recuperação do ouro presente no minério.

\section{Referências Bibliográficas}

ARAKI, C.D. Lixiviação amoniacal do minério oxidado de ouro-cobre da mina de Igarapé Bahia com tiossulfato de amônio. Relatório final de projeto de iniciação científica. 2002. Convênio CVRD/UFMG. Brasil. 37p.

DIMITRIJEVIC, M., ANTONIJEVIC, M.M., JANKOVIC, Z. Kinetics of pyrite dissolution by hydrogen peroxide in percloric acid. Revista Hydrometallurgy. v. 42. p. 377-386. 1996.

GUPTA, C.K., MUKHERJEE, T.K. Hydrometallurgy in extraction processes. CRC Press, Inc., 1990. v. 1 e 2.

MENDES, F.D. Tratamento do minério de ouro-cobre de Igarapé Bahia através de lixiviação sulfúrica seguida de cianetação. UFMG. Brasil. 116 p. 1999. (Dissertação de Mestrado).

SEVIRYUKOV, N., KUZMIN, B., CHELISHCHEV, Y. General Metallurgy. Moscow: Peace Publishers, 1980. 545 p.

\section{Artigo recebido em 16/05/2003 e} aprovado em 11/09/2003. 